\title{
Prospective evaluation of the quality of life of patients undergoing surgery for colorectal cancer depending on the surgical technique
}

\author{
Iwona Głowacka-Mrotek ${ }^{1}$ (D) - Magdalena Tarkowska ${ }^{2} \cdot$ Tomasz Nowikiewicz $^{3} \cdot$ Michał Jankowski $^{2}$ • \\ Magdalena Mackiewicz-Milewska ${ }^{1} \cdot$ Wojciech Hagner ${ }^{1} \cdot$ Wojciech Zegarski ${ }^{2}$
}

Accepted: 25 July 2019 / Published online: 8 August 2019

(C) The Author(s) 2019

\begin{abstract}
Purpose Monitoring of the quality of life of patients in addition to satisfactory survival indexes in order to choose an optimal treatment method is a trend in contemporary oncological surgery. The goal of the study was to prospectively evaluate the quality of life of patients treated for colorectal cancer depending on the type of surgical technique (open surgery (OS) vs. laparoscopic surgery (LS)).

Methods The quality of life was evaluated thrice in the study groups (on the day of admission to the ward (I), 6 months (II), and 18 months after the procedure (III)). The following questionnaires were used in this evaluation: QLQ-C30 European Organization for Research and Treatment of Cancer Quality of Life Questionnaire, QLQ-CR29 Quality of Life Questionnaire (module - colorectal cancer), and Acceptance of Illness Scale (AIS).

Results Sixty-seven patients completed this prospective clinical cohort study (LS-32; OS-35). The QLQ-C30 questionnaire demonstrated improvement in functional scales among patients treated with LS technique $(p<0.05)$ as well as with regard to overall quality of life 6 months after surgery $(p<0,001)$, while at 18 months postsurgery, statistically significant differences were noted for physical function $(p=0.001)$ and overall quality of life $(p<0.0001)$. AIS scale analysis demonstrated that patients treated with laparoscopy were characterized by better acceptance of illness $(p<0.05)$. Statistically significant differences between OS and LS groups were noted based on the QLQ-CR29 questionnaire with regard to the following scales: body image $(p=0.041)$ and body mass problem $(p=0.024)$ - patients treated with LS technique had better scores.

Conclusions Laparoscopic surgery gives patients a chance for better quality of life.
\end{abstract}

Keywords Quality of life $\cdot$ Colorectal cancer $\cdot$ Laparoscopic surgery $\cdot$ Open surgery

\section{Introduction}

Classical open surgery or laparoscopic surgery is the basis of surgical treatment of colorectal cancer [1,2]. Historical meta-

Iwona Głowacka-Mrotek and Magdalena Tarkowska are two equal first authors

What does this paper add to the literature?

In this study, we compared quality of life of patients undergoing surgery for colorectal cancer depending on the surgical technique (open vs. laparoscopic surgery). Our study showed that laparoscopic surgery is a chance for colorectal cancer patients to reach better quality of life.

Iwona Głowacka-Mrotek

iwona.glowacka@cm.umk.pl

1 Chair and Department of Rehabilitation, Ludwik Rydygier's Collegium Medicum in Bydgoszcz, Nicolaus Copernicus University in Torun, Maria Curie-Skłodowskiej Street 9,

85-094 Bydgoszcz, Poland analyses prove laparoscopic surgery to be safe and effective in terms of outcome [1, 2]. Laparoscopic surgery has been proven to be beneficial in terms of complication and pain [2-4]. Randomized clinical studies and meta-analyses show that

2 Department of Laser Therapy and Physiotherapy, Ludwik Rydygier's Collegium Medicum in Bydgoszcz, Nicolaus Copernicus University in Torun, Bydgoszcz, Poland

3 Chair and Department of Surgical Oncology, Ludwik Rydygier's Collegium Medicum in Bydgoszcz, Oncology Centre - Prof. Franciszek Łukaszczyk Memorial Hospital in Bydgoszcz, Nicolaus Copernicus University in Torun, Bydgoszcz, Poland 
colorectal surgeries performed with laparoscopic technique are associated with less blood loss during the procedure, shorter duration, faster patient mobilization, faster recovery, and better cosmetic effect [3, 4]. Colorectal cancer is one of those neoplastic diseases that significantly decrease the quality of life. Surgical and adjuvant treatment of colorectal cancer is a cause of great stress. Patients often have to change their private and professional lives, sometimes even their environment, which is undoubtedly a source of great stress and anxiety for the patient $[5,6]$. That is why research assessing physical, psychological, and social functioning of patients after successful surgery over time is so important. There are studies evaluating the quality of life of patients after surgery for colorectal cancer using open versus laparoscopic surgery. Their results vary, although some of them demonstrate better quality of life of patients treated with laparoscopic surgery [7]. Other analyses show that over a longer time perspective, surgical technique does not matter $[8,9]$. Prospective comparison of the effects of laparoscopic versus open surgery showed improvement of quality of life a week after laparoscopic surgery, but not after 1 year [10]. There is a great need for studies assessing the quality of life of patients treated with open versus laparoscopic surgery over a longer time perspective. In our study, we compared quality of live prospectively before, 6 months, and 18 months after the surgery.

The goal of our study was to perform a prospective, singlecenter evaluation of the quality of life among patients treated surgically for colorectal cancer with open versus laparoscopic surgery over an 18 -month period.

\section{Methods}

This prospective, single-center clinical cohort study was performed based on approval of Bioethical Committee of the CM UMK no. 473/2016. The study was conducted over a period 1.06.2016-20.12.2018. Successive patients referred to the Chair and Department of Oncological Surgery of CM UMK for surgical treatment of colorectal cancer were included in the study. All laparoscopies were by the same surgeon with an experience in over 200 laparoscopic procedures, while open surgeries were performed by 4 surgeons from a single team.

Inclusion criteria were as follows:

- Consent to participate in the study

- Patients referred for surgery due to colorectal cancer

- Elective surgery

- Age over 18 years

- Suitability for curative resection involving only the large intestine

- Patients qualified for open or laparoscopic surgery

- ASA I-III
- Cancer staging I-III (WHO), pTNM staging was taken into consideration

- Completion of questionnaires at subsequent stages of the study

Exclusion criteria were as follows:

- Patients qualified for reoperation

- Patients with stage IV neoplastic disease

- Patients diagnosed with metastases diagnosed in the course of the study

- Patients who required conversion during the surgical procedure

- Patient with stoma

The study design was as follows: I measurements—on the day of admission to the ward patients gave their consent to participate in the study and filled out quality-of-life questionnaire. The second examination (II measurements) took place after 6 months from surgery, while the third part of the study was conducted after 18 months from the procedure (III measurements). The second and the third examinations were performed using CATI (computer-assisted telephone interviewing).

After giving their consent to participate in the study, during the first examination, each patient responded to questions regarding age, education, place of residence, marital status, employment, or the type of planned procedure.

Information regarding clinical status of patients recorded in their medical documentation, such as qualification for particular procedure, presence and type of adjuvant treatment (neoadjuvant and adjuvant), staging of neoplastic disease, or duration of hospitalization were used for the purpose of the study.

Preoperative diagnostics encompassed: basic examinations, anesthetist's evaluation, colonoscopy, chest X-ray, tumor markers, ultrasound examination, and computed tomography of the abdomen. Mechanical bowel preparation was used before the procedure. Regardless of the method used, patients were operated on under general intravenous anesthesia. After the procedure, every patient was monitored in the postoperative room and received analgesia. All surgeries were performed by the same laparoscopic surgeon with an experience in over 200 laparoscopic procedures, while open surgeries were performed by 3 surgeons from the same team.

Quality of life of cancer patients were used in the study (European Commission for the Quality of Life Research based in Brussels agreed for use of those questionnaires):

- EORTC-QLQ-C30 European Organization for Research and Treatment of Cancer Quality of Life Questionnaire v. 3.0 - this questionnaire is used to assess physical, psychological, and social functioning. It consists of 30 questions: physical functioning (5 questions); life role 
functioning (5 questions); emotional (4); cognitive (2); and social (2) functioning; 3 symptom scalesquestions regarding malaise, nausea, vomiting, and pain; 6 individual questions regarding dyspnea, sleeplesness, loss of apetite, constipation, diarrhea, and financial difficulties. The last questions concern overall health status and its quality. The subject provided answers on a fourpoint scale (1-none to 4-very much).

- EORTC-QLQ-CR29 Quality of Life Assessment Questionnaire (colorectal cancer module) - constitutes an extension of the QLQ C30 questionnaire to include questions concerning problems of patients treated for colorectal cancer.

- AIS (Acceptance of Illness Scale) - used to assess the degree of acceptance of the disease by the patients. It contains eight statements describing negative consequences of the condition.

\section{Statistical analysis}

The statistical analysis was conducted using the IBM SPSS Statistics v. 24. The Shapiro-Wilk test was used to test the normality of distribution. Intergroup differences with regard to sociodemographic and clinical variables were assessed using chi-square test or Student's $t$ test (or its nonparametric counterpart - the Mann-Whitney $U$ test). The chi-square test and exact Fisher's test were used to analyze the qualitative data. Numerical $(n)$ and percentage (\%) values were reported. For quantitative data analysis, we used the Student's $t$ test and values were reported as means and standard deviations. In subsequent analysis, Wilcoxon's test (or $t$ test for dependent variables) was used to compare measured values. Additionally, the groups were compared separately for each measurement-immediately after the procedure, after 6 months, and after 18 months - using Mann-Whitney $U$ test (or Student's $t$ test for independent variables). For the purpose of the analysis, we assumed the value of $\alpha=0.05$.

\section{Results}

Sixty-seven patients were stratified into open $(n=35)$ and laparoscopic $(n=35)$ surgery groups. Figure 1 shows a detailed scheme of the study.

\section{Sociodemographic characteristics}

Study groups (OS vs. LS) did not differ significantly with regard to sociodemographic characteristics, such as age, sex, body mass, height, BMI, marital status, having children, level of education, employment status, or place of residence $(p<0.05)$. Results are presented in Table 1.

\section{Clinical characteristics of compared groups}

The study groups (OS and LS) were characterized with regard to clinical characteristics (Table 2). No significant differences were noted in that regard.

\section{Quality of life in compared groups}

In the next stage, we analyzed the intra-group (LS and OS) and inter-group (LS vs. OS) differences with regard to the quality of life based on the QLQ-C30 questionnaire. Results of analyses regarding physical functioning, social role functioning, cognitive, emotional and social functioning, as well as overall quality of life are presented in Table 3.

In the OS group, we observed a highly significant decrease in the quality of life between measurements I and II in the physical functioning scale $(p<0.001)$ and cognitive functioning scale as well as in the overall quality of life. Between measurements I and III, we noted a highly statistically
Fig. 1 Study scheme describing patient exclusion from the study

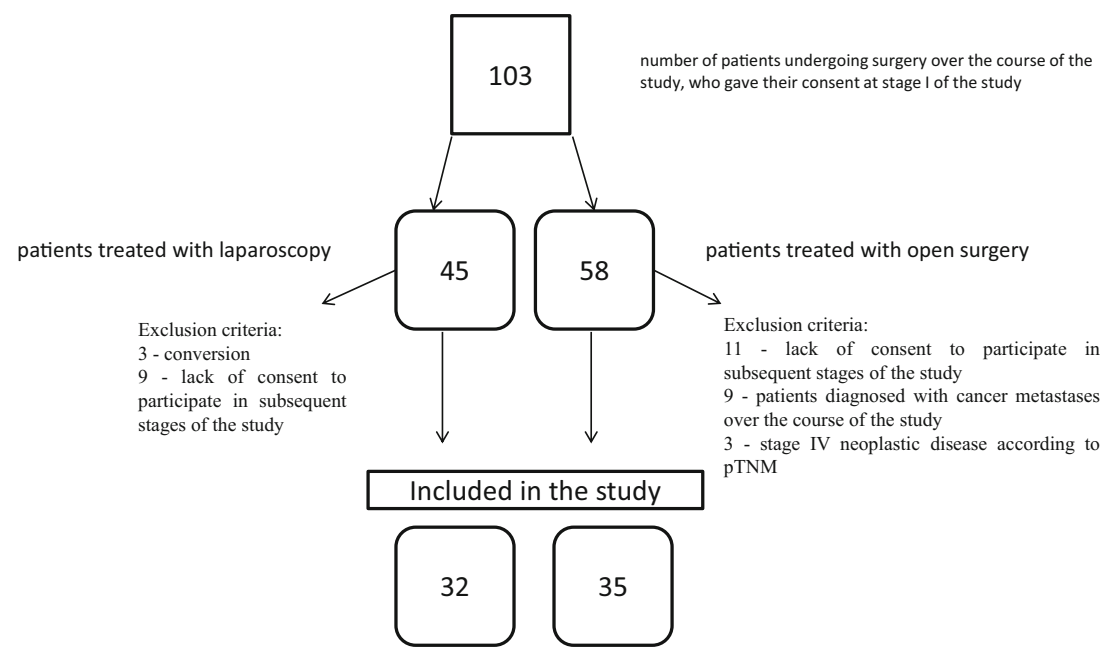


Table 1 Sociodemographic characteristics of study groups (LS vs. OS)

\begin{tabular}{|c|c|c|c|c|c|c|}
\hline & & \multicolumn{4}{|c|}{ Group } & \multirow[t]{2}{*}{$p$ value, $t$ value } \\
\hline & & \multicolumn{2}{|c|}{$\mathrm{OS}(n=35) \mathrm{M}, \mathrm{SD}$} & \multicolumn{2}{|c|}{$\mathrm{LS}(n=32) \mathrm{M}, \mathrm{SD}$} & \\
\hline Age & & 65. & & 64.1 & & 0.663 \\
\hline Sex & $\begin{array}{l}\text { Men } \\
\text { Women }\end{array}$ & $\begin{array}{l}17 \\
18\end{array}$ & $\begin{array}{l}48.6 \% \\
51.4 \%\end{array}$ & $\begin{array}{l}20 \\
12\end{array}$ & $\begin{array}{l}62.5 \% \\
37.5 \%\end{array}$ & 0.252 \\
\hline Weight & & 77. & & 15.4 & & $t(58.96)=0.494$ \\
\hline Height & & 1.68 & & 1.72 & & $t(65)=0.086$ \\
\hline BMI & & 27.2 & & 25.6 & & $t(62.89)=0.127$ \\
\hline Martial status & $\begin{array}{l}\text { Single } \\
\text { In relationship }\end{array}$ & $\begin{array}{l}15 \\
20\end{array}$ & $\begin{array}{l}42.9 \% \\
57.1 \%\end{array}$ & $\begin{array}{l}7 \\
25\end{array}$ & $\begin{array}{l}21.9 \% \\
78.1 \%\end{array}$ & 0.068 \\
\hline Children & $\begin{array}{l}\text { No } \\
\text { Yes }\end{array}$ & $\begin{array}{l}4 \\
31\end{array}$ & $\begin{array}{l}11.4 \% \\
88.6 \%\end{array}$ & $\begin{array}{l}2 \\
30\end{array}$ & $\begin{array}{l}6.3 \% \\
93.8 \%\end{array}$ & 0.458 \\
\hline Education & $\begin{array}{l}\text { Primary } \\
\text { Vocational } \\
\text { Secondary } \\
\text { Higher }\end{array}$ & $\begin{array}{l}7 \\
9 \\
16 \\
3\end{array}$ & $\begin{array}{l}20.0 \% \\
25.7 \% \\
45.7 \% \\
8.6 \%\end{array}$ & $\begin{array}{l}4 \\
6 \\
14 \\
8\end{array}$ & $\begin{array}{l}12.5 \% \\
18.8 \% \\
43.8 \% \\
25.0 \%\end{array}$ & 0.296 \\
\hline Employment & $\begin{array}{l}\text { Full time } \\
\text { Household } \\
\text { Retirement pension } \\
\text { Disability benefit } \\
\text { None } \\
\text { Own business }\end{array}$ & $\begin{array}{l}9 \\
2 \\
14 \\
4 \\
4 \\
2\end{array}$ & $\begin{array}{l}25.7 \% \\
5.7 \% \\
40.0 \% \\
11.4 \% \\
11.4 \% \\
5.7 \%\end{array}$ & $\begin{array}{l}7 \\
1 \\
18 \\
1 \\
2 \\
3\end{array}$ & $\begin{array}{l}21.9 \% \\
3.1 \% \\
56.3 \% \\
3.1 \% \\
6.3 \% \\
9.4 \%\end{array}$ & 0.605 \\
\hline Place of residence & $\begin{array}{l}\text { Country } \\
\text { City }\end{array}$ & $\begin{array}{l}14 \\
21\end{array}$ & $\begin{array}{l}40.0 \% \\
60.0 \%\end{array}$ & $\begin{array}{l}7 \\
25\end{array}$ & $\begin{array}{l}21.9 \% \\
78.1 \%\end{array}$ & 0.110 \\
\hline
\end{tabular}

$M$ mean, $S D$ standard deviation, $\chi^{2}$ chi-square, $t$ Student's $t$ test for independent variables, $p$ significance level, $O S$ patients treated with open surgery, $L S$ patients treated with laparoscopic surgery

significant decrease in the quality of life with regard to physical functioning $(p<0.001)$, significant decrease in social role functioning, cognitive functioning, and overall quality of life $(p<0.05)$. Between measurements II and III, we observed a decrease in the quality of life in the areas of emotional functioning and social functioning $(p<0.05)$.

In the LS group, we observed a highly statistically significant improvement in emotional functioning of patients $(p<0.001)$ between measurements I and III. Comparison of measurements II and III yielded significant worsening of physical functioning, cognitive functioning, and social functioning in the study group $(p<0.05)$.

Comparative analysis of OS vs. LS failed to reveal statistically significant differences in measurement I. Half a year after the procedure (measurement II), a highly significantly better result was noted in LS with regard to physical functioning and overall quality of life $(p<0.001)$ and significantly better results with regard to social role functioning, cognitive functioning, emotional functioning, and social functioning $(p<0.05)$. In measurement III, we demonstrated significantly better functioning of patients operated on using the LS technique with regard to physical functioning $(p=0.001)$ and a highly significant increase in overall quality of life $(p<0.001)$.
The analysis of symptoms based on the QLQ-C30 questionnaire (Table 4) revealed a statistically significant decrease in malaise and dyspnea in the OS group between measurements I and II $(p<0.05)$, diarrhea between measurements I and III, and dyspnea between measurements II and III $(p<0.05)$. In the LS group, we noted a statistically significant reduction in sleeping disturbances between measurements I and II, decrease in nausea and vomiting, pain, and loss of appetite; between measurements II and III, we observed a decrease in fatigue, nausea, and vomiting as well as loss of appetite $(p<0.05)$. Inter-group comparison yielded a statistically significant reduction in the feeling of malaise in measurement III $(p<0.05)$ among the LS group.

We performed an analysis of the quality of life in the examined groups using the QLQ-C29 questionnaire (Table 5). In the OS group, statistically significant differences between measurements were noted for the female sexual interest scale between measurements I and II $(p=0.020)$. Before surgery, women exhibited a higher level of sexual interest than 6 months afterward. In the LS group, a statistically significant improvement was noted between measurements I and II, as well as in the anxiety and body mass problem scales between measurements I and III. Inter-group comparisons (LS vs. OS) 
Table 2 Clinical characteristics of study groups (LS vs. OS)

\begin{tabular}{|c|c|c|c|}
\hline & $\mathrm{OS}(n=35) \mathrm{M}, \mathrm{SD}$ & $\mathrm{LS}(n=32) \mathrm{M}, \mathrm{SD}$ & Statistics \\
\hline Duration of hospitalization & $7.88 ; 4.40$ & $6.97 ; 1.82$ & $U=449.0 ; p=0.200$ \\
\hline Number of complications & $0.11 ; 0.40$ & $0.09 ; 0.30$ & $U=557.0 ; p=0.939$ \\
\hline \multicolumn{4}{|l|}{ Type of surgical procedure } \\
\hline Hemicolectomy & $9(20 \%)$ & $8(21.9 \%)$ & \\
\hline Anterior resection of the rectum & $20(57.1 \%)$ & $17(37.6 \%)$ & \multirow{2}{*}{ Fisher's exact test $p=0.892$} \\
\hline Sigmoid resection & $6(11.4 \%)$ & $6(21.9 \%)$ & \\
\hline \multicolumn{3}{|l|}{ Preoperative adjuvant treatment } & \multirow{3}{*}{$\begin{array}{l}\mathrm{X}^{2}(1)=0.176 ; p=0.675 \\
\text { Fisher's exact test } \\
p=0.806 \text { (two-sided) }\end{array}$} \\
\hline RTH & $16(45.7 \%)$ & $13(44.8 \%)$ & \\
\hline None & $19(54.3 \%)$ & $19(59.4 \%)$ & \\
\hline \multicolumn{3}{|l|}{ Postoperative adjuvant treatment } & \\
\hline RTH & $1(2.9 \%)$ & $0(0 \%)$ & \\
\hline CHTH & $12(34.3 \%)$ & $13(40.6 \%)$ & \\
\hline None & $22(62.9 \%)$ & $19(46.3 \%)$ & \\
\hline \multicolumn{4}{|l|}{ Degree of clinical advancement } \\
\hline I & $7(20.0 \%)$ & $5(15.6 \%)$ & \multirow{3}{*}{$\chi^{2}(2)=1.675 ; p=0.433$} \\
\hline II & $10(28.6 \%)$ & $14(43.8 \%)$ & \\
\hline III & $18(51.4 \%)$ & $13(40.6 \%)$ & \\
\hline
\end{tabular}

$M$ mean, $S D$ standard deviation, $\chi^{2}$ chi-square test, $U$ Mann-Whitney test, $p$ significance, $L S$ patients treated with laparoscopic surgery, $O S$ patients treated with open surgery, $C H T H$ chemotherapy, $R T H$ radiotherapy

yielded significantly better outcomes for the LS group in the anxiety scale and body mass problem scale $(p<0.05)$ as well as in the body image scale, anxiety scale, and body mass problem scale in measurement III $(p<0.05)$.

\section{Level of acceptance of illness among studied groups}

Outcomes in the AIS scale are reported in Table 6.

There were no statistically significant differences within the OS and LS groups in the AIS scale. Statistically significant differences were noted between the LS and OS groups. In all three measurements, patients after laparoscopy demonstrated a higher level of acceptance of illness $(p<0.05)$.

\section{Discussion}

In our study, we assessed the quality of life of patients treated for colorectal cancer depending on the used surgical technique (open vs. laparoscopic surgery) over an 18-month period. Standard questionnaires QLQ-C30, QLQ-C29, and AIS were used for evaluation. The analysis of the QLQ-C30 and QLQ-C29 questionnaires failed to reveal statistically significant differences within study groups before surgery. We observed worsening of the quality of life in functional scales in both groups (QLQ-30). After 6 months from surgery, we noted a significantly better quality of life among patients treated laparoscopically with regard to physical functioning, social role functioning, cognitive functioning, emotional functioning, social functioning, and overall quality of life. In the third measurement performed, 19 months after the procedure, significant improvement in the quality of life was noted in the LS group in the QLQ-C30 scale with regard to physical functioning and overall quality of life. The analysis of QLQ-C29 showed a significant difference in outcomes with regard to the symptom of malaise and body mass problems - patients operated on using the LS technique functioned better in that respect. The analysis of the scale of acceptance of illness (QLQ-C30 questionnaire) demonstrated a significantly lower level of malaise among patients treated with the LS technique 18 months after the procedure. Analysis of the AIS results showed a greater level of acceptance of illness among all patients in the LS group throughout all stages of the study.

The strengths of our study include its prospective and singlecenter nature as well as an 18-month follow-up period. There are a lot of studies comparing laparoscopic and open surgical techniques [8-11]. Some of them have reported improved health-related quality of life (HRQL) [8, 10], and some of them have shown no difference between $[9,11]$. Clinical trials conducted by Andersson et al. showed that QLQ after rectal cancer surgery was not affected by surgical approach [8]. Study conducted by Braga et al. showed that laparoscopic colorectal resection was associated with a better quality of life in the first 12 months after surgery compared with open surgery [11]. Our study showed in some aspect (physical functioning and overall quality of life) better results in group treated with laparoscopic surgery 18 months after surgery.

Previous studies contain data collected over shorter periods of time, and their results vary [8-11]. 
Table 3 Change in the quality of life in the studied patient groups (LS and OS) and assessment of dependency between the groups (LS vs OS based on QLQ-C30 questionnaire

\begin{tabular}{|c|c|c|c|c|c|c|c|c|c|}
\hline \multirow{3}{*}{$\begin{array}{l}\text { EORTC-QLQ C-30 } \\
\text { Functional scales (the best score } 100 \text { pts }\end{array}$} & \multicolumn{4}{|c|}{ OS $(n=35)$} & \multicolumn{4}{|c|}{$\operatorname{LS}(n=32)$} & \\
\hline & \multicolumn{3}{|c|}{ Arithmetic mean } & & \multicolumn{3}{|c|}{ Arithmetic mean } & & \\
\hline & I & II & III & & I & II & III & & \\
\hline Physical functioning & $\begin{array}{l}85.52 \\
14.95\end{array}$ & $\begin{array}{l}68.38 \\
14.49\end{array}$ & $\begin{array}{l}64.38 \\
12.93\end{array}$ & $\begin{array}{l}\text { I vs II } \\
p<0.001 \\
\text { I vs III } \\
p<0.001 \\
\text { II vs III } \\
p>0.05\end{array}$ & $\begin{array}{l}86.46 \\
12.38\end{array}$ & $\begin{array}{l}88.54 \\
13.68\end{array}$ & $\begin{array}{l}80.21 \\
17.96\end{array}$ & $\begin{array}{l}\text { I vs II } \\
p>0.05 \\
\text { I vs III } \\
p>0.05 \\
\text { II vs III } \\
p=0.026\end{array}$ & $\begin{array}{l}\text { I } p=0.990 \\
U=559.0 \\
\text { II } p<0.001 \\
U=174.0 \\
\text { III } p=0.001 \\
U=286.0\end{array}$ \\
\hline Functioning in social roles & $\begin{array}{l}79.05 \\
28.68\end{array}$ & $\begin{array}{l}70.00 \\
24.85\end{array}$ & $\begin{array}{l}66.19 \\
25.08\end{array}$ & $\begin{array}{l}\text { I vs II } \\
p>0.05 \\
\text { I vs III } \\
p=0.024 \\
\text { II vs III } \\
p>0.05\end{array}$ & $\begin{array}{l}81.77 \\
23.71\end{array}$ & $\begin{array}{l}82.81 \\
20.07\end{array}$ & $\begin{array}{l}72.40 \\
26.98\end{array}$ & $\begin{array}{l}\text { I vs II } \\
p>0.05 \\
\text { I vs III } \\
p>0.05 \\
\text { II vs III } \\
p>0.05\end{array}$ & $\begin{array}{l}\text { I } p=0.840 \\
U=545.0 \\
\text { II } p=0.031 \\
U=399.0 \\
\text { III } p=0.307 \\
U=483.0\end{array}$ \\
\hline Cognitive functioning & $\begin{array}{l}76.67 \\
19.89\end{array}$ & $\begin{array}{l}67.62 \\
20.59\end{array}$ & $\begin{array}{l}66.67 \\
18.52\end{array}$ & $\begin{array}{l}\text { I vs II } \\
p=0.025 \\
\text { I vs III } \\
p=0.011 \\
\text { II vs III } \\
p>0.05\end{array}$ & $\begin{array}{l}76.04 \\
20.27\end{array}$ & $\begin{array}{l}83.33 \\
15.84\end{array}$ & $\begin{array}{l}69.27 \\
21.63\end{array}$ & $\begin{array}{l}\text { I vs II } \\
p>0.05 \\
\text { I vs III } \\
p>0.05 \\
\text { II vs III } \\
p=0.002\end{array}$ & $\begin{array}{l}\text { I } p=0.902 \\
U=550.5 \\
\text { II } p=0.002 \\
U=316.0 \\
\text { III } p=0.552 \\
U=514.0\end{array}$ \\
\hline Emotional functioning & $\begin{array}{l}65.95 \\
26.07\end{array}$ & $\begin{array}{l}75.24 \\
24.38\end{array}$ & $\begin{array}{l}62.62 \\
28.89\end{array}$ & $\begin{array}{l}\text { I vs II } \\
p>0.05 \\
\text { I vs III } \\
p>0.05 \\
\text { II vs III } \\
p=0.034\end{array}$ & $\begin{array}{l}66.67 \\
23.76\end{array}$ & $\begin{array}{l}90.63 \\
16.90\end{array}$ & $\begin{array}{l}72.14 \\
27.48\end{array}$ & $\begin{array}{l}\text { I vs II } \\
p<0.001 \\
p>0.05 \\
\text { II vs III } \\
p=0.001\end{array}$ & $\begin{array}{l}\text { I } p=0.845 \\
\mathrm{U}=544.5 \\
\text { II } p=0.009 \\
\mathrm{U}=363.5 \\
\mathrm{III} p=0.192 \\
\mathrm{U}=458.0\end{array}$ \\
\hline Social functioning & $\begin{array}{l}79.05 \\
25.03\end{array}$ & $\begin{array}{l}77.62 \\
19.78\end{array}$ & $\begin{array}{l}69.05 \\
21.82\end{array}$ & $\begin{array}{l}\text { I vs II } \\
p>0.05 \\
\text { I vs III } \\
p>0.05 \\
\text { II vs III } \\
p=0.036\end{array}$ & $\begin{array}{l}83.85 \\
22.19\end{array}$ & $\begin{array}{l}88.54 \\
17.68\end{array}$ & $\begin{array}{l}77.08 \\
24.23\end{array}$ & $\begin{array}{l}\text { I vs II } \\
p>0.05 \\
\text { I vs III } \\
p>0.05 \\
\text { II vs III } \\
p=0.016\end{array}$ & $\begin{array}{l}\text { I } p=0.392 \\
U=497.0 \\
\text { II } p=0.017 \\
U=384.0 \\
\text { III } p=0.137 \\
U=446.0\end{array}$ \\
\hline General quality of life & $\begin{array}{l}45.31 \\
14.50\end{array}$ & $\begin{array}{l}30.73 \\
19.22\end{array}$ & $\begin{array}{l}35.42 \\
19.74\end{array}$ & $\begin{array}{l}\text { I vs II } \\
p=0.003 \\
\text { I vs III } \\
p=0.023 \\
\text { II vs III } \\
p>0.05\end{array}$ & $\begin{array}{l}50.48 \\
19.17\end{array}$ & $\begin{array}{l}51.67 \\
10.07\end{array}$ & $\begin{array}{l}53.81 \\
14.20\end{array}$ & $\begin{array}{l}\text { I vs II } \\
\mathrm{Z}=p>0.05 \\
\text { I vs III } \\
p>0.05 \\
\text { II vs III } \\
Z=p>0.05\end{array}$ & $\begin{array}{l}\text { I } p=0.106 \\
U=433.5 \\
\text { II } p<0.001 \\
U=183.0 \\
\text { III } p<0.001 \\
U=225.0\end{array}$ \\
\hline
\end{tabular}

EORTC-QLQ-C30 European Organization for Research and Treatment of Cancer Quality of Life Questionnaire, $L S$ patients treated with laparoscopic surgery, $O S$ patients treated with open surgery, $I$ examination 1 day prior to surgery, $I I$ examination 6 months following surgery, $I I I$ examination 18 months following surgery, $p$ level of significance, $Z$ Wilcoxon's test, $U$ Mann-Whitney test

QLQ-C30 and QLQ-C29 tools used in this study were often used in other studies; thus, they constitute a good starting point for discussion [12-14]. In our study, we were using same tools. Study conducted by Janson et al. showed that laparoscopic surgery improved general quality of life during first postoperative month [12]. Our measurement showed better quality of life patient treated with laparoscopic surgery 6 months after surgical intervention. Very interesting findings are shown in the study conducted by Theodoropoulos et al. [13]. Results presented in this research showed better quality of life over the first year after laparoscopic colectomy than before surgery. In our study, in the LS group, we found better emotional functioning 18 months after surgery than before surgery. The review of 22 studies presented by Theodoropoulos et al. showed no long-term beneficial effects of laparoscopic surgery on patient QLQ [14]. In our study, we observed quality of life of our patient during the first 18 months after surgery. The differences between study groups in the course of time were less visible.

Moreover, our study was broadened by the analysis of acceptance of illness based on the AIS scale. It showed a decrease in the quality of life in functional scales over time in the OS group 
Table 4 Analysis of symptom scales before and after surgical procedure in two groups (LS vs OS and assessment of relations between the groups (LS vs OS) based on QLQ-C30 questionnaire

\begin{tabular}{|c|c|c|c|c|c|c|c|c|c|}
\hline \multirow{3}{*}{$\begin{array}{l}\text { EORTC-QLQ-C } 30 \\
\text { Symptom scales (the best score } 0 \text { pts. }\end{array}$} & \multicolumn{4}{|l|}{ OS $(n=35)$} & \multicolumn{4}{|c|}{$\operatorname{LS}(n=32)$} & \\
\hline & \multicolumn{3}{|l|}{ Mean } & & \multicolumn{3}{|l|}{ Mean } & & \\
\hline & I & II & III & & I & II & III & & \\
\hline Fatigue & $\begin{array}{l}26.98 \\
18.92\end{array}$ & $\begin{array}{l}40.95 \\
20.48\end{array}$ & $\begin{array}{l}32.70 \\
24.39\end{array}$ & $\begin{array}{l}\text { I vs II } \\
p=0.005 \\
\text { I vs III } \\
p>0.05 \\
\text { II vs III } \\
p>0.05\end{array}$ & $\begin{array}{l}25.69 \\
17.72\end{array}$ & $\begin{array}{l}32.64 \\
23.09\end{array}$ & $\begin{array}{l}18.75 \\
22.12\end{array}$ & $\begin{array}{l}\text { I vs II } \\
p>0.05 \\
\text { I vs II } \\
p>0.05 \\
\text { II vs III } \\
p=0.007\end{array}$ & $\begin{array}{l}\text { I } p=0.887 \\
U=549.0 \\
\text { II } p=0.122 \\
U=439 \\
\text { III } p=0.015 \\
U=370.0\end{array}$ \\
\hline Nausea and vomiting & $\begin{array}{l}5.71 \\
18.50\end{array}$ & $\begin{array}{l}5.24 \\
10.52\end{array}$ & $\begin{array}{l}2.38 \\
9.17\end{array}$ & $\begin{array}{l}\text { I vs II } \\
p>0.05 \\
\text { I vs III } \\
p>0.05 \\
\text { II vs III } \\
p>0.05\end{array}$ & $\begin{array}{l}8.33 \\
19.40\end{array}$ & $\begin{array}{l}8.85 \\
16.39\end{array}$ & $\begin{array}{l}0.52 \\
2.95\end{array}$ & $\begin{array}{l}\text { I vs II } \\
p>0.05 \\
\text { I vs III } \\
p=0.016 \\
\text { II vs III } \\
p=0.011\end{array}$ & $\begin{array}{l}\text { I } p=0.308 \\
U=504.0 \\
\text { II } p=0.505 \\
U=519.5 \\
\text { III } p=0.343 \\
U=529.0\end{array}$ \\
\hline Pain & $\begin{array}{l}27.14 \\
25.27\end{array}$ & $\begin{array}{l}23.81 \\
21.12\end{array}$ & $\begin{array}{l}23.33 \\
25.31\end{array}$ & $\begin{array}{l}\text { I vs II } \\
p>0.05 \\
\text { I vs III } \\
p>0.05 \\
\text { II vs III } \\
p>0.05\end{array}$ & $\begin{array}{l}24.48 \\
23.56\end{array}$ & $\begin{array}{l}18.75 \\
18.33\end{array}$ & $\begin{array}{l}13.54 \\
18.66\end{array}$ & $\begin{array}{l}\text { I vs II } \\
p>0.05 \\
\text { I vs III } \\
p=0.045 \\
\text { II vs III } \\
p>0.05\end{array}$ & $\begin{array}{l}\text { I } p=0.696 \\
U=530.0 \\
\text { II } p=0.355 \\
U=489.5 \\
\text { III } p=0.120 \\
U=444.5\end{array}$ \\
\hline Dyspnea & $10.48(\mathrm{SD}-15.70$ & $\begin{array}{l}22.86 \\
23.94\end{array}$ & $\begin{array}{l}14.29 \\
23.27\end{array}$ & $\begin{array}{l}\text { I vs II } \\
p=0.012 \\
\text { I vs III } \\
p>0.05 \\
\text { II vs III } \\
p=0.029\end{array}$ & $\begin{array}{l}7.29 \\
16.36\end{array}$ & $\begin{array}{l}16.67 \\
29.33\end{array}$ & $\begin{array}{l}10.42 \\
21.48\end{array}$ & $\begin{array}{l}\text { I vs II } \\
p>0.05 \\
\text { I vs III } \\
p>0.05 \\
\text { II vs III } \\
p>0.05\end{array}$ & $\begin{array}{l}\text { I } p=0.277 \\
U=494.5 \\
\text { II } p=0.117 \\
U=449.0 \\
\text { III } p=0.479 \\
U=515.5\end{array}$ \\
\hline Sleeping disturbances & $\begin{array}{l}29.52 \\
33.11\end{array}$ & $\begin{array}{l}32.38 \\
30.77\end{array}$ & $\begin{array}{l}35.24 \\
37.87\end{array}$ & $\begin{array}{l}\text { I vs II } \\
p>0.05 \\
\text { I vs III } \\
p>0.05 \\
\text { II vs III } \\
p>0.05\end{array}$ & $\begin{array}{l}26.04 \\
34.64\end{array}$ & $\begin{array}{l}11.46 \\
20.05\end{array}$ & $\begin{array}{l}20.83 \\
27.76\end{array}$ & $\begin{array}{l}\text { I vs II } \\
p=0.025 \\
\text { I vs III } \\
p>0.05 \\
\text { II vs III } \\
p>0.05\end{array}$ & $\begin{array}{l}\text { I } p=0.374 \\
U=494.5 \\
\text { II } p=0.002 \\
U=340.5 \\
\text { III } p=0.140 \\
U=451.5\end{array}$ \\
\hline Loss of appetite & $\begin{array}{l}5.24 \\
11.27\end{array}$ & $\begin{array}{l}4.76 \\
8.64\end{array}$ & $\begin{array}{l}2.38 \\
9.17\end{array}$ & $\begin{array}{l}\text { I vs II } \\
p>0.05 \\
\text { I vs III } \\
p>0.05 \\
\text { II vs III } \\
p>0.05\end{array}$ & $\begin{array}{l}7.29 \\
13.35\end{array}$ & $\begin{array}{l}8.33 \\
15.84\end{array}$ & $\begin{array}{l}0.52 \\
2.95\end{array}$ & $\begin{array}{l}\text { I vs II } \\
p>0.05 \\
\text { I vs III } \\
p=0.010 \\
\text { II vs III } \\
p=0.010\end{array}$ & $\begin{array}{l}\text { I } p=0.558 \\
U=524.5 \\
\text { II } p=0.645 \\
U=531.5 \\
\text { III } p=0.343 \\
U=529.0\end{array}$ \\
\hline Constipation & $\begin{array}{l}29.52 \\
33.11\end{array}$ & $\begin{array}{l}20.95 \\
25.67\end{array}$ & $\begin{array}{l}19.05 \\
30.56\end{array}$ & $\begin{array}{l}\text { I vs II } \\
p>0.05 \\
\text { I vs III } \\
p>0.05 \\
\text { II vs III } \\
p>0.05\end{array}$ & $\begin{array}{l}18.75 \\
28.00\end{array}$ & $\begin{array}{l}21.88 \\
31.23\end{array}$ & $\begin{array}{l}19.79 \\
30.36\end{array}$ & $\begin{array}{l}\text { I vs II } \\
p>0.05 \\
\text { I vs III } \\
p>0.05 \\
\text { II vs III } \\
p>0.05\end{array}$ & $\begin{array}{l}\text { I } p=0.135 \\
U=451.5 \\
\text { II } p=0.850 \\
U=546.5 \\
\text { III } p=0.848 \\
U=547.0\end{array}$ \\
\hline Diarrhea & $\begin{array}{l}23.81 \\
33.89\end{array}$ & $\begin{array}{l}17.14 \\
29.56\end{array}$ & $\begin{array}{l}9.52 \\
23.67\end{array}$ & $\begin{array}{l}\text { I vs II } \\
p>0.05 \\
\text { I vs III } \\
p=0.043 \\
\text { II vs III } \\
p>0.05\end{array}$ & $\begin{array}{l}28.13 \\
37.39\end{array}$ & $\begin{array}{l}11.46 \\
23.36\end{array}$ & $\begin{array}{l}19.79 \\
33.72\end{array}$ & $\begin{array}{l}\text { I vs II } \\
p>0.05 \\
\text { I vs III } \\
p>0.05 \\
\text { II vs III } \\
p>0.05\end{array}$ & $\begin{array}{l}\text { I } p=0.683 \\
U=531.0 \\
\text { II } p=0.480 \\
U=515.5 \\
\text { III } p=0.160 \\
U=0.476 .5\end{array}$ \\
\hline
\end{tabular}

EORTC-QLQ-C30 European Organization for Research and Treatment of Cancer Quality of Life Questionnaire, $L S$ patients treated with laparoscopic surgery, $O S$ patients treated with open surgery, $I$ examination 1 day prior to surgery, $I I$ examination 6 months following surgery, $I I I$ examination 18 months following surgery, $p$ level of significance, $Z$ Wilcoxon's test, $U$ Mann-Whitney test 
Table 5 Analysis of body image, anxiety, body mass problems, and sexual functioning prior to and after surgical procedure in two groups (LS vs OS and assessment of relations between the groups (LS vs OS) based on QLQ-C29 questionnaire)

\begin{tabular}{|c|c|c|c|c|c|c|c|c|c|}
\hline \multirow{3}{*}{$\begin{array}{l}\text { EORTC-QLQ-C29 } \\
\text { Functional scales (the best score } 100 \text { pts }\end{array}$} & \multicolumn{4}{|c|}{ OS $(n=35)$} & \multicolumn{4}{|c|}{$\operatorname{LS}(n=32)$} & \\
\hline & \multicolumn{2}{|l|}{ Mean } & \multirow[b]{2}{*}{ III } & & \multicolumn{2}{|l|}{ Mean } & \multirow[b]{2}{*}{ III } & & \\
\hline & I & II & & & I & II & & & \\
\hline \multirow[t]{6}{*}{ Body image } & 81.27 & 72.06 & 72.38 & I vs II & 86.46 & 83.68 & 85.07 & I vs II & $\mathrm{I} p=0.173$ \\
\hline & 21.86 & 34.34 & 32.15 & $p>0.05$ & 21.44 & 25.86 & 26.26 & $p>0.05$ & $U=457.0$ \\
\hline & & & & I vs III & & & & I vs III & II $p=0.130$ \\
\hline & & & & $p>0.05$ & & & & $p>0.05$ & $U=446.5$ \\
\hline & & & & II vs III & & & & II vs III & III $p=0.041$ \\
\hline & & & & $p>0.05$ & & & & $p>0.05$ & $U=406.5$ \\
\hline \multirow[t]{7}{*}{ Anxiety } & 38.57 & 38.10 & 49.52 & I vs II & 31.25 & 53.13 & 60.42 & I vs II & I $p=0.119$ \\
\hline & 21.67 & 24.45 & 26.04 & $p>0.05$ & 28.00 & 26.59 & 26.01 & $Z=-2.344$ & $U=383.0$ \\
\hline & & & & I vs III & & & & $p=0.019$ & II $p=0.022$ \\
\hline & & & & $p>0.05$ & & & & I vs III & $U=390.5$ \\
\hline & & & & II vs III & & & & $Z=-3.494$ & III $p=0.039$ \\
\hline & & & & $p>0.05$ & & & & $p<0.001$ & $U=421.0$ \\
\hline & & & & & & & & $\begin{array}{l}\text { II vs III } \\
p>0.05\end{array}$ & \\
\hline \multirow[t]{6}{*}{ Body mass problem } & 77.14 & 82.86 & 77.14 & I vs II & 75.00 & 93.75 & 92.71 & I vs II & $\mathrm{I} p=1.000$ \\
\hline & 22.54 & 21.95 & 32.11 & $p>0.05$ & 29.33 & 15.70 & 16.36 & $p=0.003$ & $U=560.0$ \\
\hline & & & & I vs III & & & & I vs III & II $p=0.017$ \\
\hline & & & & $p>0.05$ & & & & $p=0.003$ & $U=407.5$ \\
\hline & & & & II vs III & & & & II vs III & III $p=0.024$ \\
\hline & & & & $p>0.05$ & & & & $p>0.05$ & $U=413.0$ \\
\hline \multirow[t]{6}{*}{ Sexual interests men } & 33.33 & 27.78 & 27.45 & I vs II & 34.92 & 30.16 & 36.51 & I vs II & $\mathrm{I} p=0.181$ \\
\hline & 24.34 & 30.78 & 26.97 & $p>0.05$ & 22.30 & 23.34 & 23.34 & $p>0.05$ & $U=146.0$ \\
\hline & & & & I vs III & & & & I vs III & II $p=0.687$ \\
\hline & & & & $p>0.05$ & & & & $p>0.05$ & $U=156.0$ \\
\hline & & & & II vs III & & & & II vs III & III $p=0.263$ \\
\hline & & & & $p>0.05$ & & & & $p=0.206$ & $U=143.0$ \\
\hline \multirow[t]{6}{*}{ Sexual interest women } & 25.49 & 12.28 & 20.37 & I vs II & 24.24 & 27.27 & 36.36 & I vs II & $\mathrm{I} p=0.537$ \\
\hline & 18.74 & 19.91 & 25.92 & $p<0.05$ & 30.15 & 25.03 & 27.71 & $p>0.05$ & $U=82.0$ \\
\hline & & & & I vs III & & & & I vs III & II $p=0.080$ \\
\hline & & & & $p>0.05$ & & & & $p>0.05$ & $U=68.5$ \\
\hline & & & & II vs III & & & & II vs III & III $p=0.122$ \\
\hline & & & & $p>0.05$ & & & & $p>0.05$ & $U=67.0$ \\
\hline
\end{tabular}

EORTC-QLQ-C29 European Organization for Research and Treatment of Cancer Quality of Life Questionnaire Colorectal Cancer module, $L S$ patients treated with laparoscopic surgery, $O S$ patients treated with open surgery, $I$ examination 1 day prior to surgery, $I I$ examination 6 months following surgery, III examination 18 months following surgery, $p$ level of significance, $Z$ Wilcoxon's test, $U$ Mann-Whitney test

and in the LS group, as was demonstrated in the study by Jayne et al. [15]. The author hypothesized that worsening of the quality of life among patients treated surgically with laparoscopy might be associated with the kind of support that patents receive after surgery. Other authors observed an improvement in quality of life outcomes compared to those observed before surgery $[13,16]$.

In our study, we observed better outcomes with regard to the results of functional scales and overall quality of life 6 months after the procedure among patients treated with laparoscopy, which is consistent with the results reported by other authors [7]. Better outcomes in functional scales among patients treated laparoscopically observed 6 months after the procedure might be explained by better results in recovery compared to patients treated with open surgery. In our opinion, better functioning of patients who had undergone laparoscopic procedure might also be associated with patients' opinion that it is a less invasive procedure used in milder types of neoplasms.
Over time, the differences in results of functional scales between operated groups of patients became smaller. After 18 months from the procedures, statistically significant differences in favor of LS were only noted for the physical functioning scale and overall quality of life. Other authors came to similar conclusions [17-19]. Other studies comparing quality of life after 39 months failed to show differences in the quality of life between laparoscopic and open surgery [20]. Prospective comparison of quality of live after open versus laparoscopic surgery conducted by $\mathrm{Li}$ and colleagues showed improvement of quality of life week after laparoscopic surgery, but not after 1 year [10]. Our study showed that as time passed from surgery, the differences in QLQ between laparoscopic and open surgery group were less visible.

The analysis of symptom scales of the QLQ-C30 questionnaire showed a statistically significant increase in malaise and dyspnea 6 months after surgery. It might be connected with the 
Table 6 Acceptance of illness in the studied patient groups (LS and OS and assessment of dependency between the groups (LS vs OS based on AIS questionnaire)

\begin{tabular}{|c|c|c|c|c|c|c|c|c|c|}
\hline \multirow[t]{3}{*}{ (AIS } & \multicolumn{4}{|c|}{$\operatorname{LS}(n=35)$} & \multicolumn{4}{|c|}{ OS $(n=32)$} & \\
\hline & \multicolumn{3}{|l|}{ Mean } & & \multicolumn{3}{|l|}{ Mean } & & \\
\hline & I & II & III & & I & II & III & & \\
\hline Acceptance of illness & $\begin{array}{l}27.31 \\
6.50\end{array}$ & $\begin{array}{l}25.54 \\
5.24\end{array}$ & $\begin{array}{l}26.23 \\
5.79\end{array}$ & $\begin{array}{l}\text { I vs II } \\
p=0.229 \\
\text { I vs III } \\
p=0.519 \\
\text { II vs III } \\
p=0.493\end{array}$ & $\begin{array}{l}31.00 \\
7.42\end{array}$ & $\begin{array}{l}30.06 \\
5.93\end{array}$ & $\begin{array}{l}31.25 \\
5.34\end{array}$ & $\begin{array}{l}\text { I vs II } \\
p=0.581 \\
\text { I vs III } \\
p=0.884 \\
\text { II vs III } \\
p=0.423\end{array}$ & $\begin{array}{l}\text { I } p=0.034 \\
\text { II } p=0.002 \\
\text { III } p<0.001\end{array}$ \\
\hline
\end{tabular}

AIS Acceptance of Illness Scale, $L S$ patients treated with laparoscopic surgery, $O S$ patients treated with open surgery, $I$ examination 1 day prior to surgery, II examination 6 months following surgery, III examination 18 months following surgery, $p$ level of significance

symptoms accompanying postoperative management and reduced mobility of patients treated with an open technique. Generally, after 18 months from surgery a decrease in symptoms associated with treatment of both LS as well as OS patients was observed. Statistical significance was noted for the LS group with regard to malaise, nausea, vomiting, pain, trouble sleeping, and loss of appetite. Comparison of results between the LS and OS groups demonstrated a statistically significant difference in the severity of symptoms of malaise in the studied groups of patients with greater intensity of symptoms observed in the group treated with OS. No significant differences were noted between the groups with regard to the remaining symptom scales. Prospective comparison of quality of live after open versus laparoscopic surgery conducted by $\mathrm{Li}$ and colleagues showed improvement of quality of life week after laparoscopic surgery, but not after 1 year [10]. Our study showed that as time passed from surgery, the differences in QLQ between laparoscopic and open surgery group were less visible.

The analysis of the QLQ-C29 questionnaire showed a statistically significant difference - a reduction in symptoms was observed in the LS group with regard to anxiety and body mass problem. Inter-group comparison demonstrated differences with respect to anxiety and body mass problem 6 months after the procedure-decreased severity was observed in the LS group. Eighteen months after the procedure, we noted statistical difference with respect to body mass image, anxiety, and body mass problem in favor of the LS group. Body image issues are common among patients treated with open surgery, which may be due to larger postoperative wound and financial status [10].

After 6 months from surgery, we observed a drop in sexual interest in both study groups - changes were statistically significant in the OS group; our findings were similar to the other studies [21, 22].

Determination of the degree of disease acceptance based on the AIS scale is one of the strengths of our study. There were no differences in outcomes in the AIS scale between groups in successive measurements. There was, however, a higher level of acceptance of illness in the LS group before surgery, half a year afterward and 18 months after the procedure. In our opinion, this result may be explained by a common belief of minimal invasiveness of laparoscopic techniques.

Our study was a single-center study. In Poland, patients with colorectal cancer do not receive any standard psychological support programs. Therefore, our study results differ in many ways from those of other authors. Randomized studies and meta-analyses demonstrate that patients who receive psychological support over the course of treatment for colorectal cancer have improved quality of life [23-26].

This study presents several limitations. Firstly, this is not a randomized study. Another limitation of our study is the time point when the first measurement was taken - the day before surgery, when patients are usually anxious because of the upcoming procedure. Small study groups also constitute a weak point of this study.

\section{Conclusion}

Our study demonstrated improved quality of life and higher degree of acceptance of illness among patients treated with LS compared to OS. In both groups, we observed a reduction in the quality of life according to functional scales (QLQ-C30 questionnaire) over time after surgery. Patients treated with the LS technique demonstrated greater acceptance of the disease. This study shows that regardless of the type of procedure performed, patients require psychological support. Our study showed some practical guidelines. Colorectal cancer patients should be informed that after laparoscopic surgery they will feel emotionally and physically better. Our study has also supplied knowledge to the surgical team that less invasive methods are providing colorectal cancer patients chance for better quality of life. 
Funding information Grant support for the study was received from the Ministry of Science and Higher Education of Poland No. MN-6/WNoZ/ 2016. The financial sponsors had no role in study design, data collection and analysis, or preparation of the article. The authors have no financial interest in any of the products or devices mentioned in this article.

\section{Compliance with ethical standards}

The project was approved by the Bioethics Committee of Collegium Medicum in Bydgoszcz (KB 473/2016).

Conflict of interest The authors declare that they have no conflict of interest.

Informed consent Informed consent was obtained from all individuals participants included in the study.

Open Access This article is distributed under the terms of the Creative Commons Attribution 4.0 International License (http:// creativecommons.org/licenses/by/4.0/), which permits unrestricted use, distribution, and reproduction in any medium, provided you give appropriate credit to the original author(s) and the source, provide a link to the Creative Commons license, and indicate if changes were made.

\section{References}

1. Veldkamp R, Kuhry E, Hop WC, Jeekel J, Kazemier G, Bonjer HJ et al (2005) Laparoscopic surgery versus open surgery for colon cancer: short-term outcomes of a randomised trial. Lancet Oncol 6(7):477-484

2. Hyde LZ, Baser O, Mehendale S, Guo D, Shah M, Kiran RP (2019) Impact of surgical approach on short-term oncological outcomes and recovery following low anterior resection for rectal cancer. Color Dis 5:7. https://doi.org/10.1111/codi.14677

3. Ng KT, Tsia AKV, Chong VYL (2019) Robotic versus conventional laparoscopic surgery for colorectal cancer: a systematic review and meta-analysis with trial sequential analysis. World J Surg 43(4):11461161

4. Nordholm-Carstensen A, Jensen KK, Krarup PM (2018) Oncological outcome following laparoscopic versus open surgery for cancer in the transverse colon: a nationwide cohort study. Surg Endosc 232(10):4148-4157

5. Harrington Deimling GT, Albitz C, Monnin K, Renzhofer Pappada HT, Nalepa E, Boehm ML, Mitchell C (2017) Personality and psychological distress among older adult, long-term cancer survivors. J Psychosoc Oncol 35(1): 17-31

6. Hearing M (2012) Health-promotion behaviors and psychological distress in cancer survivors. Oncol Nurs Forum 39(2):132-140

7. Fujii S, Ota M, Ichikawa Y, Yamagishi S, Watanabe K, Tatsumi K, Watanabe J, Suwa H, Oshima T, Kunisaki C, Ohki S, Endo I, Shimada H (2010) Comparison of short, long-term surgical outcomes and mid-term health-related quality of life after laparoscopic and open resection for colorectal cancer: a case-matched control study. Int J Color Dis 25:1311-1323

8. Andersson J, Angenete E, Gellerstedt M, Angerås U, Jess P, Rosenberg J, Fürst A, Bonjer J, Haglind E (2013) Health-related quality of life after laparoscopic and open surgery for rectal cancer in a randomized trial. Br J Surg 100(7):941-949

9. Eshuis EJ, Slors JF, Stokkers PC, Sprangers MA, Ubbink DT, Cuesta MA et al (2010) Long-term outcomes following laparoscopically assisted versus open ileocolic resection for Crohn's disease. Br J Surg 97:563-568
10. Li J, Chen R, Xu YQ, Wang XC, Zheng S, Zhang SZ, Ding KF (2010) Impact of a laparoscopic resection on the quality of life inrectal cancer patients: results of 135 patients. Surg Today 40:917-922

11. Braga M, Frasson M, Vignal A, Zuliani W, Civelli V, Di Carlo V (2005) Laparoscopic vs. open colectomy in cancer patients: long term complications, quality of life, and survival. Dis Colon Rectum 48:2217-2223

12. Janson M, Lindholm E, Anderberg B, Haglind E (2007) Randomized trial of health-related quality of life after open and laparoscopic surgery for colon cancer. Surg Endosc 21:747-753

13. Theodoropoulos GE, Karantanos T, Stamopoulos P, Zografos G (2013) Prospective evaluation of health-related quality of life after laparoscopic colectomy for cancer. Tech Coloproctol 17(1):27-38

14. Theodoropoulos GE, Karantanos T (2014) Quality of life after laparoscopic colectomy for cancer. JSLS 18(2):225-235

15. Jayne DG, Guillou PJ, Thorpe H, Quirke P, Copeland J, Smith AM et al (2007) Randomized trial of laparoscopic-assisted resection of colorectal carcinoma: 3-year results of the UK MRCCLASICC Trial Group. J Clin Oncol 25:3061-3068

16. Siassi M, Weiss M, Hohenberger W, Losel F, Matzel K (2009) Personality rather than clinical variables determines quality of life after major colorectal surgery. Dis Colon Rectum 52:662-668

17. Scarpa M, Erroi F, Ruffolo C, Mollica E, Polese L, Pozza G, Norberto L, D'Amico DF, Angriman I (2009) Minimally invasive surgery for colorectal cancer: quality of life, body image, cosmesis, and functional results. Surg Endos 23(3):577-582

18. Seitz G, Seitz EM, Kasparek MS, Konigsrainer A, Kreis ME (2008) Long-term quality-of-life after open and laparoscopic sigmoid colectomy. Surg Laparosc Endosc Percutan Tech 18(2):162-167

19. Patankar SK, Larach SW, Ferrara A, Williamson PR, Gallagher JT, DeJesus S, Narayanan S (2003) Prospective comparison of laparoscopic vs. open resections for colorectal adenocarcinoma over a tenyear period. Dis Colon Rectum 46(5):601-611

20. Psaila J, Bulley SH, Ewings P, Sheffield JP, Kennedy RH (1998) Outcome following laparoscopic resection for colorectal cancer. $\mathrm{Br}$ J Surg 85:662-664

21. Lin YH, Chen HP, Liu KW (2010) Fecal incontinence and quality of life in adults with rectal cancer after lower anterior resection. $\mathrm{J}$ Wound Ostomy Continence Nurs 42(4):395-400

22. Stamopoulos P, Theodoropoulos GE, Papailiou J, Savidis D, Golemati C, Bramis K, Panoussopoulos SG, Leandros E (2009) Prospective evaluation of sexual function after open and laparoscopic surgery for rectal cancer. Surg Endosc 23(12):2665-2674

23. Morino M, Parini U, Allaix ME, Monasterolo G, Brachet Contul R, Garrone C (2009) Male sexual and urinary function after laparoscopic total mesorectal excision. Surg Endosc 23(6):1233-1240

24. Heesook S, Youn-Jung S, Hyerang K, Yoonju L (2018) Effect of psychosocial interventions on the quality of life of patients with colorectal cancer: a systematic review and meta-analysis. Health Qual Life Outcomes 8(16):119

25. Mosher CE, Winger JG, Given BA, Shahda S, Helft PR (2017) A systematic review of psychosocial interventions for colorectal cancer patients. Support Care Cancer 25(7):1-14

26. Tourani S, Behzadifar M, Martini M, Aryankhesal A, Taheri Mirghaed M, Salemi M, Behzadifar M, Bragazzi NL (2018) Health-related quality of life among healthy elderly Iranians: a systematic review and meta-analysis of the literature. Health Qual Life Outcomes 16:18

Publisher's note Springer Nature remains neutral with regard to jurisdictional claims in published maps and institutional affiliations. 